\title{
Management of ruptured intracranial aneurysms in the post-ISAT era: outcome of surgical clipping versus endovascular coiling in a Singapore tertiary institution
}

\author{
Roy Kok Miang $\underline{K o h}^{1}$, FRCs, Zhixu $\underline{\mathrm{Ng}}^{1}$, MBBS, MRCs, Sharon Yin Yee $\underline{L o w}^{2}$, MBBS, MRCs, Felicia Hui Zhuang $\underline{C h u a}^{3}$,
} Ning Chou $^{4}$, FRCS, Shiong Wen Low ${ }^{4}$, FRCS, Tseng Tsai $\underline{Y e O}^{4}$, FRACS

\begin{abstract}
INTRODUCTION The results of the International Subarachnoid Aneurysm Trial (ISAT) in 2002 have significantly influenced the management of ruptured intracranial aneurysms. There is now an established shift worldwide toward endovascular coiling as the initial treatment of choice. We assessed the outcomes of patients admitted to our institution for aneurysmal subarachnoid haemorrhage (SAH), comparing the outcomes of patients (World Federation of Neurosurgical Societies [WFNS] grades 1-3) who underwent surgical clipping versus those who underwent endovascular coiling.

METHODS We retrospectively reviewed patients admitted to the National University Hospital for SAH secondary to ruptured intracranial aneurysm in 2005-2009. Patients were divided into two groups - clipping and coiling. Data on individual demographics, comorbidities, Fisher grading and Glasgow Outcome Scale scores were collected for the two groups and subjected to relevant statistical analyses.

RESULTS Of the 133 patients admitted for nontraumatic SAH, 89 had ruptured aneurysms. Among the 56 patients classified as WFNS grades 1-3, 23 underwent coiling while the remaining 33 underwent clipping. A significant association was found between Fisher grade and the likelihood of developing hydrocephalus in these patients.

CONCLUSION Although we acknowledge the presence of management bias in our institution, our findings were similar to those of the ISAT trial. Upon correlation between our results and current evidence-based findings, our findings show that clipping provides similar long-term outcomes as endovascular coiling. In the event that an aneurysm is deemed unsuitable for coiling, clipping remains an effective option.
\end{abstract}

Keywords: endovascular coiling, intracranial aneurysm, subarachnoid haemorrhage, surgical clipping

\section{INTRODUCTION}

Subarachnoid haemorrhage $(\mathrm{SAH})$ secondary to intracranial aneurysm rupture remains one of the most serious neurosurgical emergencies today. Intracranial aneurysms are acquired cerebrovascular anomalies that develop throughout a patient's lifetime. (1) They are arterial lesions defined by thinned and dilated regions of the cerebrovascular wall that exhibit loss of the internal elastic lamina, thinning of the tunica media, and subsequent remodelling and degradation of extracellular matrix proteins throughout the vessel wall. Most aneurysms occur at bifurcation sites along the Circle of Willis, as these areas are prone to haemodynamic patterns that potentiate aneurysm development. ${ }^{(2)}$

The key to minimising the risk of rebleeding following aneurysmal rupture is to isolate the aneurysm from its cerebral circulation. In this regard, surgical clipping and endovascular coiling are both effective, although there has been much debate on the merits of each intervention. ${ }^{(1)}$ However, the International Subarachnoid Aneurysm Trial (ISAT) in 2002 has caused a paradigm shift in the management of ruptured intracranial aneurysms toward a preference for endovascular coiling versus surgical clipping. ${ }^{(3)}$ Furthermore, the recent Barrow Ruptured Aneurysm Trial (BRAT) conducted by McDougall et al also concluded that patients who underwent surgical clipping were 1.68 times more likely to have poor outcomes compared to those who underwent endovascular coiling. ${ }^{(4)}$ While the ISAT concluded that there was better disability-free survival and a risk reduction in dependency or death with endovascular coiling compared to surgery, ${ }^{(3)}$ there has been much criticism of the trial, as was eloquently highlighted by the BRAT study. For example, it has been cited that in the ISAT, almost $80 \%$ of aneurysms were excluded, the proficiencies between the different interventionists and neurosurgeons were varied, and the types of recruiting centres as well as type and location of aneurysms between groups had wide differences. ${ }^{(3,4)}$ Furthermore, the subsequent five-year follow-up data of the ISAT suggest that the benefit in outcome seen at six months had vanished over the ensuing years. ${ }^{(5)}$ However, the current results of the ongoing BRAT study have shown that a policy of intent to treat by endovascular coiling results in a reduction of poor clinical outcome at one-year of follow-up..$^{(4)}$

Our study was a retrospective audit of our institution's experience in the management of ruptured intracranial aneurysms. We assessed the overall outcomes of patients admitted for SAH secondary to aneurysmal bleeding, and

${ }^{1}$ Division of Neurosurgery, Khoo Teck Puat Hospital, ${ }^{2}$ Department of Neurosurgery, National Neuroscience Institute, Singapore, ${ }^{3}$ Faculty of Medicine, Nursing and Health Sciences, Monash Medical School, Monash University, Melbourne, Australia, ${ }^{4}$ Division of Neurosurgery, National University Health System, Singapore 


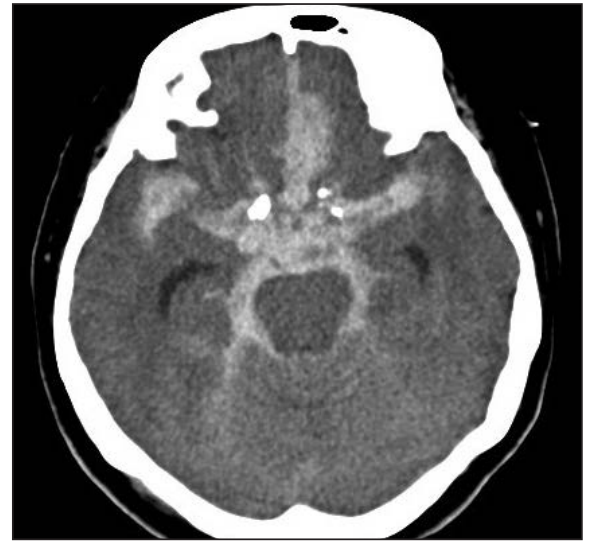

Fig. 1 Axial non-contrast CT image shows high attenuation within the subarachnoid spaces, representative of spontaneous subarachnoid haemorrhage secondary to intracranial aneurysm rupture.

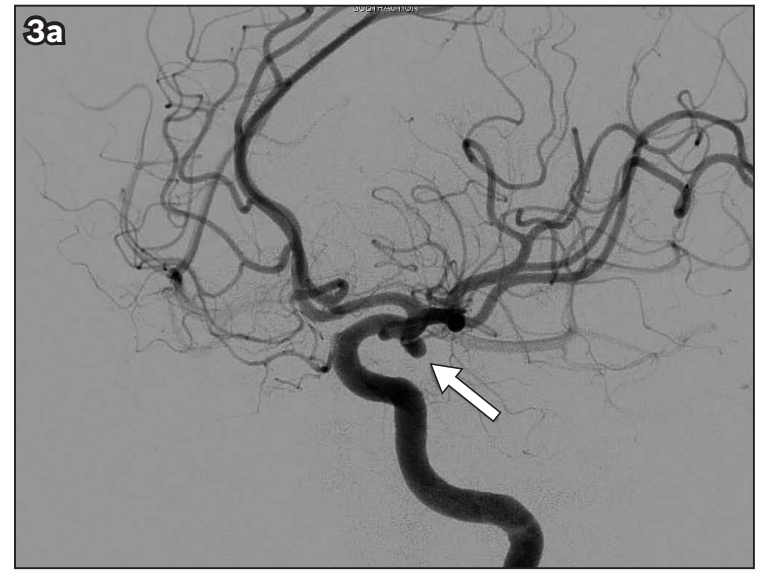

Fig. 3 Lateral digital subtraction angiography images show a left posterior communicating artery aneurysm (a) precoiling (arrow points to aneurysm) and (b) postcoiling (arrow points to the coil).

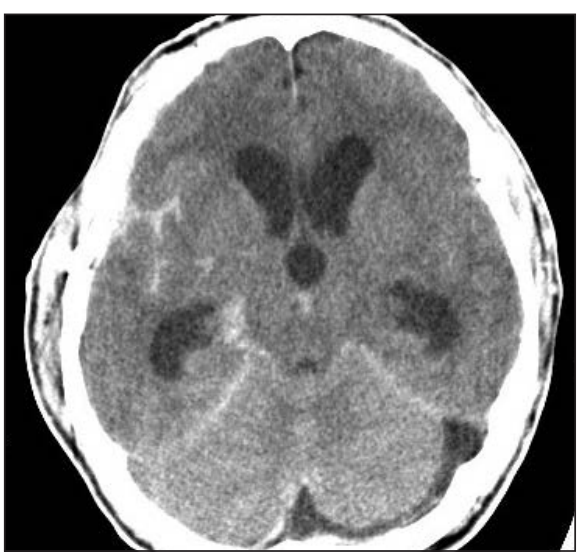

Fig. 2 Axial non-contrast CT image shows post-subarachnoid haemorrhage hydrocephalus.

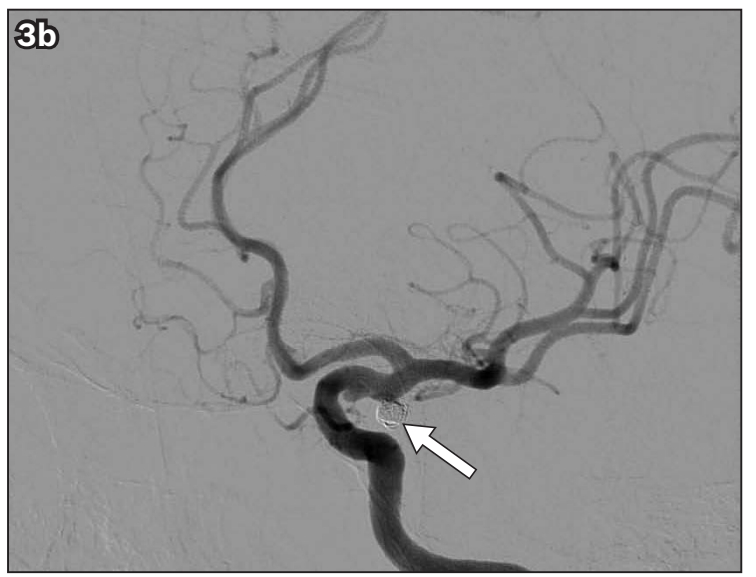

In addition, we selected a group of patients with WFNS grades 1-3 $\mathrm{SAH}$ and compared the treatment outcomes of those who underwent endovascular coiling (Fig. 3) against those who underwent surgical clipping (Fig. 4). Fig. 5 shows the results of this comparison. For these patients, Glasgow Outcome Scale (GOS) scores were collected approximately six months after discharge and used as a measure of their neurological and functional outcomes. The GOS is a five-point score applied to victims of traumatic brain injury. It is also widely used in SAH patients for assessment of outcomes (Table I). Patients with a GOS score of 1,2 and 3 were collectively grouped as 'poor outcome', while those with GOS scores of 4 and 5 were termed as 'good outcome'. Furthermore, the eventual need for post-treatment ventriculoperitoneal (VP) shunting was used as a variable to compare outcomes between patients from the endovascular coiling and surgical clipping groups. Patients who declined treatment or died before treatment and those with incomplete follow-up data six months after discharge were excluded from the final data analysis.

Data were analysed using the Statistical Package for the Social Sciences for Windows version 17.0 (SPSS Inc, Chicago, IL, USA). Chi-square test was used to compare the outcome of patients who were treated with endovascular coiling versus surgical clipping based on their GOS scores. The odds ratio (OR) 

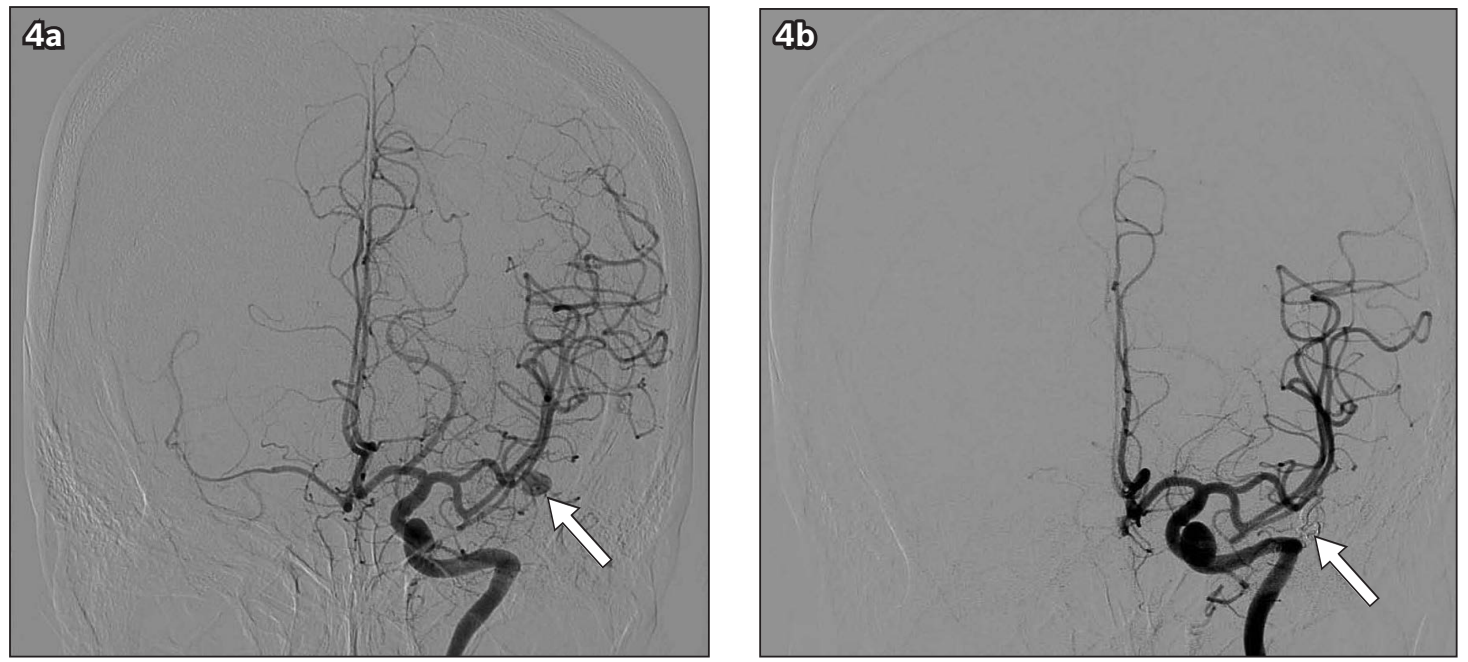

Fig. 4 Anteroposterior digital subtraction angiography images show a left middle cerebral artery aneurysm (a) preclipping (arrow points to aneurysm) and (b) postclipping (arrow points to the surgical clip).

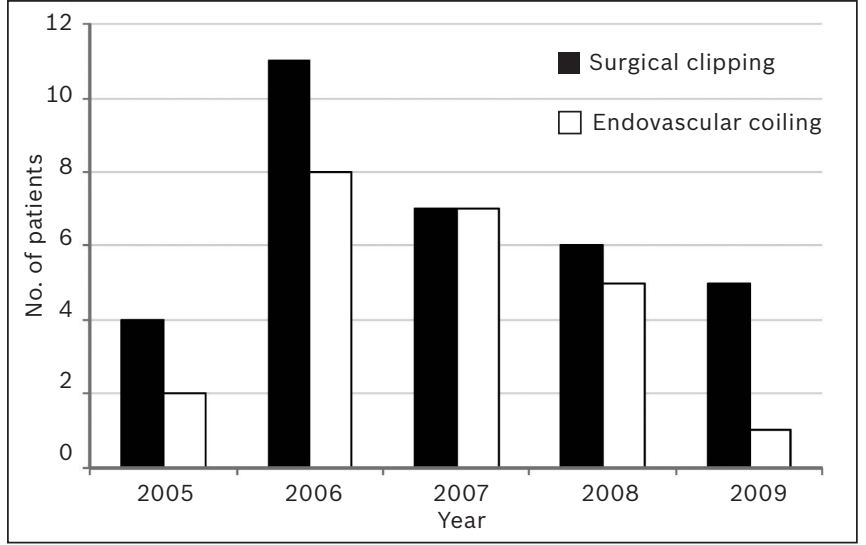

Fig. 5 Graph shows the annual number of patients with World Federation of Neurosurgical Societies grades 1-3 subarachnoid haemorrhages admitted and treated for ruptured intracranial aneurysms during the study period.

of association was calculated to compare outcomes between the two patient groups, using logistic regression to adjust for various significant confounders. Unpaired Student's t-test was used to compare the differences in length of hospital stay between the two groups.

\section{RESULTS}

During the study period, a total of 133 patients with nontraumatic SAH suspected to be secondary to aneurysmal rupture were managed at our institution. Of these, 89 patients had aneurysms that were confirmed on CT or digital subtraction angiography. The aneurysms in this cohort of patients were saccular in nature. The study excluded 119 patients who had other types of aneurysms, such as those that were traumatic or dissecting in nature. Of the 60 patients who were classified as WFNS grades $1-3$, four were excluded due to death prior to treatment $(n=2)$ and refusal of any form of intervention despite advice $(n=2)$. In total, 56 patients classified as WFNS grades 1-3 were finally found to be suitable for inclusion in the study. The remaining 29 patients who were classified as WFNS grades 4-5 upon admission were excluded from the analyses.
Table I. The Glasgow Outcome Scale (GOS) and scores of study patients $(\mathrm{n}=\mathbf{8 9})$.

\begin{tabular}{llc}
\hline $\begin{array}{l}\text { GOS } \\
\text { score }\end{array}$ & Outcome & No. (\%) \\
\hline 1 & Dead & $16(18.0)$ \\
2 & $\begin{array}{l}\text { Vegetative state (patient is unresponsive, } \\
\text { but alive) }\end{array}$ & $4(4.5)$ \\
3 & $\begin{array}{l}\text { Severely disabled (patient is conscious, but } \\
\text { requires daily support from others due } \\
\text { to disability) }\end{array}$ & $13(14.6)$ \\
4 & $\begin{array}{l}\text { Moderately disabled (patient is } \\
\text { independent, but disabled) }\end{array}$ & $7(7.9)$ \\
5 & $\begin{array}{l}\text { Good recovery (patient has resumed most } \\
\text { normal activities, but may have minor } \\
\text { residual problems) }\end{array}$ & $49(55.1)$ \\
\hline
\end{tabular}

The mean age of the patients was 54.5 years and the mean GCS on admission was 12.3. Men comprised $38 \%$ of the patients admitted and the average length of hospital stay was 19.8 days. Based on initial CT findings, there were 12 (13.5\%), $15(16.9 \%), 23(25.8 \%)$ and $39(43.8 \%)$ patients with Fisher grades 1, 2, 3 and 4, respectively. 16 (18.0\%) patients died due to ruptured intracranial aneurysms. $17(19.1 \%)$ patients had poor outcomes (GOS 2 and 3) while 56 (62.9\%) patients had good outcomes (GOS 4 and 5) (Table I).

Our study showed a significant positive association between Fisher grade and the likelihood of developing post-SAH hydrocephalus. Compared to patients with Fisher grades 1 and 2 combined, the likelihood of hydrocephalus developing in patients with Fisher grades 3 and 4 were 4.7 times (95\% confidence interval $[\mathrm{Cl}] 1.2-18.1 ; \mathrm{p}=0.02)$ and 16.5 times $(95 \%$ Cl 4.6-59.6; $\mathrm{p}<0.01$ ) higher, respectively (Table II). Similarly, Fisher grade also showed a significant positive association with EVD insertion rates - patients with grades 3 and 4 were 1.5 times (95\% Cl 0.4-5.0; $\mathrm{p}=0.55)$ and 6.4 times $(95 \% \mathrm{Cl} 2.1-19.3$; $\mathrm{p}=0.01$ ) more likely to require EVD insertion, respectively, when compared to patients with Fisher grades 1 and 2 combined. 
Table II. Fisher grades of patients admitted for ruptured aneurysms and patients who developed hydrocephalus.

\begin{tabular}{|c|c|c|c|c|}
\hline \multirow[t]{2}{*}{ Fisher grade } & \multicolumn{2}{|c|}{ No. (\%) } & \multirow[t]{2}{*}{$\mathrm{OR}^{*}(95 \% \mathrm{Cl})^{+}$} & \multirow[t]{2}{*}{ p-value } \\
\hline & Present & Absent & & \\
\hline \multicolumn{5}{|l|}{$1 \& 2(n=27)$} \\
\hline EVD insertion & $7(25.9)$ & $20(74.1)$ & 1 & \\
\hline VP shunt & $6(22.2)$ & $21(77.8)$ & 1 & \\
\hline \multicolumn{5}{|l|}{$3(n=23)$} \\
\hline EVD insertion & $8(34.8)$ & $15(63.2)$ & $1.5(0.4-5.0)$ & 0.55 \\
\hline VP shunt & $3(13.0)$ & $20(87.0)$ & $0.5(0.1-2.5)$ & 0.42 \\
\hline \multicolumn{5}{|l|}{$4(n=39)$} \\
\hline Hydrocephalus & $30(76.9)$ & $9(23.1)$ & $16.5(4.6-59.5)$ & $<0.01$ \\
\hline EVD insertion & $27(69.2)$ & $12(30.8)$ & $6.4(2.1-19.3)$ & 0.01 \\
\hline VP shunt & $14(35.9)$ & $25(64.1)$ & $2.1(0.6-6.5)$ & 0.22 \\
\hline
\end{tabular}

*Odds ratio of association was controlled for the presence of confounding factors such as age, gender and comorbidities using logistic regression.

${ }^{\dagger}$ Test of trends of odds ratio across Fisher grades for hydrocephalus, EVD insertion and VP shunt insertion were < $0.01,0.01$ and 0.15 , respectively.

$\mathrm{Cl}$ : confidence interval; EVD: external ventricular drain; OR: odds ratio; VP: ventriculoperitoneal

Table III. Characteristics of patients admitted for ruptured aneurysms.

\begin{tabular}{|c|c|c|c|c|}
\hline \multirow[t]{2}{*}{ Variable } & \multicolumn{2}{|c|}{ No. (\%) } & \multirow[t]{2}{*}{$95 \% \mathrm{Cl}$} & \multirow[t]{2}{*}{ p-value } \\
\hline & Clipping $(n=33)$ & Coiling $(n=23)$ & & \\
\hline Men & $15(45.5)$ & $8(34.8)$ & & $0.43^{*}$ \\
\hline Age $^{\ddagger}$ (yrs) & $54.1 \pm 13.9$ & $52.8 \pm 11.6$ & -5.8 to 8.34 & $0.72^{+}$ \\
\hline GCS on arrival ${ }^{*}$ & $14.6 \pm 0.6$ & $14.7 \pm 0.5$ & -0.4 to 0.2 & $0.48^{\dagger}$ \\
\hline Length of stay (days) & $16.1 \pm 8.9$ & $17.2 \pm 11.9$ & -6.6 to 4.5 & 0.71 \\
\hline Mortality & $3(9.1)$ & $2(8.7)$ & & 0.96 \\
\hline $\begin{array}{l}\text { Ethnicity } \\
\text { Chinese } \\
\text { Malay } \\
\text { Eurasian } \\
\text { Indian } \\
\text { Other }\end{array}$ & $\begin{aligned} 21 & (63.6) \\
3 & (9.1) \\
0 & (0) \\
8 & (24.2) \\
1 & (3.0)\end{aligned}$ & $\begin{aligned} 15 & (65.2) \\
1 & (4.3) \\
2 & (8.7) \\
3 & (13.0) \\
2 & (8.7)\end{aligned}$ & & $0.29^{*}$ \\
\hline $\begin{array}{l}\text { Anterior circulation aneurysm } \\
\text { A2/pericallosal } \\
\text { Internal carotid artery } \\
\text { Anterior communicating artery } \\
\text { Middle cerebral artery } \\
\text { Posterior communicating artery }\end{array}$ & $\begin{array}{ll}2 & (6.1) \\
8 & (24.2) \\
7 & (21.2) \\
7 & (21.2) \\
7 & (21.2)\end{array}$ & $\begin{array}{ll}1 & (4.3) \\
1 & (4.3) \\
9 & (39.1) \\
1 & (4.3) \\
6 & (26.1)\end{array}$ & & $0.045^{*}$ \\
\hline $\begin{array}{l}\text { Posterior circulation aneurysm } \\
\text { Posterior cerebral artery } \\
\text { Vertebral artery }\end{array}$ & $\begin{array}{l}1(3.0) \\
1(3.0)\end{array}$ & $\begin{array}{l}0(0) \\
5(21.7)\end{array}$ & & $0.045^{*}$ \\
\hline $\begin{array}{l}\text { Fisher grade } \\
1 \\
2 \\
3 \\
4\end{array}$ & $\begin{aligned} 5 & (15.2) \\
10 & (30.3) \\
6 & (18.2) \\
12 & (36.4)\end{aligned}$ & $\begin{array}{ll}4 & (17.4) \\
2 & (8.7) \\
9 & (39.1) \\
8 & (34.8)\end{array}$ & & 0.016 \\
\hline
\end{tabular}

${ }^{*}$ p-value was calculated using the chi-square test. ${ }^{\dagger} p$-value was calculated using Student's $t$-test with $95 \% \mathrm{Cl}$. ${ }^{\ddagger}$ Data is presented as mean \pm standard deviation. $\mathrm{Cl}$ : confidence interval; GCS: Glasgow Coma Scale

The test of trends of the OR across Fisher grades for both hydrocephalus $(p<0.01)$ and EVD insertion $(p=0.01)$ were statistically significant. However, there was no significant relationship between Fisher grade and VP shunt insertion rates for patients with grades 3 (OR 0.5, 95\% $\mathrm{Cl} 0.1-2.5 ; \mathrm{p}=0.42$ ) and 4 (OR 2.1, 95\% Cl 0.6-6.9; $\mathrm{p}=0.22$ ).

Out of the 56 patients who were classified as WFNS grades $1-3$ and who received treatment for ruptured aneurysms, $23(41.1 \%)$ underwent coiling while 33 (58.9\%) underwent surgical clipping. The demographic data of the patients from these two groups, including mean age, gender ratio, ethnicity, aneurysm circulation and mean GCS scores on arrival, were found to be relatively similar (Table III). Hypertension (39.3\%) and hyperlipidaemia (21.4\%) were the most common comorbidities among the patients in our study (Table IV). The mean length of hospital stay for patients who underwent surgical clipping was shorter than those treated by coiling, although the difference was not statistically significant (16.1 days vs. 17.2 days; $p=0.71$ ).

Based on GOS scores, patients who underwent surgical clipping had a larger percentage of poor outcomes at six months follow-up when compared to those who underwent endovascular coiling, with an absolute difference of $5.2 \%$, although the result was not statistically significant $(18.2 \%$ vs. 
Table IV. Comorbidities of patients admitted for ruptured aneurysms.

\begin{tabular}{|c|c|c|c|c|}
\hline \multirow[t]{2}{*}{ Variable } & \multicolumn{2}{|c|}{ No. (\%) } & \multirow[t]{2}{*}{$\chi^{2}(\mathrm{df})$} & \multirow[t]{2}{*}{ p-value * } \\
\hline & Clipping $(n=33)$ & Coiling $(n=23)$ & & \\
\hline Hypertension & $11(33.3)$ & $11(47.8)$ & $30(1)$ & 0.28 \\
\hline Diabetes mellitus & 0 & $2(8.7)$ & 0.002 (1) & 0.085 \\
\hline
\end{tabular}

* Statistical significance was calculated using chi-square test with $95 \%$ confidence interval.

df: degrees of freedom

Table V. Comparison of outcomes of patients who underwent coiling and patients who underwent clipping for ruptured aneurysms.

\begin{tabular}{|c|c|c|c|c|c|}
\hline \multirow[t]{2}{*}{ Variable } & \multicolumn{2}{|c|}{ No. (\%) } & \multirow[t]{2}{*}{$\mathrm{OR}^{+}(95 \% \mathrm{Cl})$} & \multirow[t]{2}{*}{$\chi^{2}(\mathrm{df})$} & \multirow[t]{2}{*}{ p-value } \\
\hline & Clipping $(n=33)$ & Coiling ( $n=23$ ) & & & \\
\hline Outcome & & & $1.5(0.3-7.1)$ & $0.27(1)$ & $0.61^{*}, 0.61^{+}$ \\
\hline Poor & $6(18.2)$ & $3(13.0)$ & & & \\
\hline Good & $27(81.8)$ & $20(87.0)$ & & & \\
\hline VP shunt & & & $1.8(0.5-6.8)$ & $0.74(1)$ & $0.39^{*}, 0.40^{+}$ \\
\hline Required & $9(27.2)$ & $4(17.4)$ & & & \\
\hline
\end{tabular}

* Statistical significance calculated using chi-square test with $95 \% \mathrm{Cl}$ for outcome and VP shunt. Student's $t$-test with $95 \% \mathrm{Cl}$ was used to calculate statistical significance for mean length of stay. ${ }^{\dagger}$ Odds ratio of association was controlled for the presence of confounding factors such as age, gender and comorbidities using logistic regression. $\mathrm{Cl}$ : confidence interval; df: degrees of freedom; OR: odds ratio; VP: ventriculoperitoneal

$13.0 \% ; p=0.61$ ) (Table V). Using logistic regression to calculate the OR of association, we found that patients who underwent surgical clipping were 1.5 times more likely to have poor outcomes compared to those who were treated using coiling, although this result was also not statistically significant $(95 \% \mathrm{Cl}$ $0.3-7.1 ; p=0.61$ ) (Table V).

Our study also showed that patients who underwent surgical clipping had a higher incidence of VP shunt insertion than those who underwent endovascular coiling, although this difference was not statistically significant $(16.1 \%$ vs. $7.1 \%$; $p=0.39$ ). Using logistic regression to adjust for confounders such as age, gender and comorbidities, we found that patients who underwent surgical clipping were 1.8 times more likely to require VP shunts than patients who received coiling. Although our results were not statistically significant $(95 \% \mathrm{Cl} 0.4-7.1$; $p=0.39$ ), it should be noted that our overall study group had a higher absolute percentage.

\section{DISCUSSION}

The management of ruptured intracranial aneurysms is a common challenge faced by neurosurgeons. The disease is an acute neurosurgical emergency, with a significant fatality rate of $40 \%-60 \%$. ${ }^{(6)}$ Studies reveal that $3.6 \%-6 \%$ of the population over the age of 30 years harbour unruptured intracranial aneurysms. ${ }^{(7)}$ There is a danger that these vessels might rupture, causing SAH and potential infarct of cerebral parenchyma. ${ }^{(8)}$

The annual incidence of aneurysmal SAH in Western countries is reported to be $6-8$ per 100,000 people. ${ }^{(9)}$ The overall mortality of the disease is $32 \%-67 \%$, with $30 \%$ of survivors having moderate-to-severe disability. ${ }^{(10)}$ Only $35 \%$ of patients have good cognitive outcomes. ${ }^{(8)}$ Although the mortality among patients presenting with aneurysmal SAH in our study was $18.0 \%$, and $19.1 \%$ of our patients had poor outcomes (GOS 2 and 3 ) based on GOS, our findings are based on a shorter follow-up period compared to other studies. It is therefore possible that our outcomes may not be completely reflective of long-term eventuality among such patients.

Since the publication of the ISAT results, our institution has practised a policy of consultating with an interventional radiologist about the management of all patients admitted with aneurysms, with regard to the suitability of coiling prior to the consideration of open surgery as a treatment option. All cases involving patients with ruptured aneurysms, who are deemed fit to undergo treatment, were also discussed with the interventional radiologist upon confirmed diagnosis during admission. The results of the ISAT has thus influenced our preference for endovascular coiling, as its short- and long-term follow-up results have shown lower morbidity when compared to those following open surgical clipping of aneurysms. We acknowledge that this bias would likely be a significant confounder affecting our study results. However, given the improved efficacy of endovascular treatment, as demonstrated by the ISAT, it is not considered inappropriate clinical practice to offer it as a first-line modality.

Our results indicate that patients who underwent surgical clipping were 1.5 times more likely to have poor outcomes than those who underwent endovascular coiling. We believe that this result is clinically significant, as our institution practises endovascular treatment for patients with aneurysms as a firstline option over surgery. As interventional radiologists were given first-line selection of patients, this might have given rise to significant selection bias. Patients who were deemed unsuitable for endovascular treatment, such as those with aneurysms that the interventional radiologist felt could not be occluded, were scheduled to undergo open neurosurgical treatment. We acknowledge that such an approach may have been associated with different technical challenges owing to the varied patient factors and/or anatomical nuances contributing to the decision on the suitability of endovascular coiling versus surgical clipping in our patients. As evidenced by our results, there was 
a notable difference in the type and location of aneurysms that underwent clipping when compared to endovascular coiling. For instance, a significantly higher percentage of patients underwent clipping than coiling for middle cerebral artery (MCA) aneurysms (21.2\% vs. $4.3 \%)$ in our study. This finding is in agreement with studies that showed a preference for surgical clipping in the treatment of MCA aneurysms. ${ }^{(11)}$ Similarly, a significant percentage of our patients underwent endovascular coiling for vertebral artery aneurysms as compared to those who underwent clipping (3.0\% vs. $21.7 \%$ ).

Our study was limited by a small sample size and relatively short follow-up periods. We were consequently unable to convincingly prove a statistically significant relationship between surgical clipping of patients with ruptured aneurysms and poorer outcome within the context of our institution. However, given the small absolute difference (5.2\%) and OR (1.5) observed in our cohort, we opine that surgical clipping remains a viable alternative for the treatment of aneurysms.

The selection of patients who were mainly WFNS grades $1-3$ in our study was in keeping with the practices preferred by a majority of neurosurgeons. This implies that neurosurgeons tend to be more aggressive toward good-grade aneurysmal patients with $\mathrm{SAH}$ by offering aggressive treatment early, as aneurysmal rebleeds are associated with dismal outcomes, with a markedly reduced chance of survival with functional independence. ${ }^{(12)}$ Such patients will benefit from early treatment. In cases where an interventional radiologist is not available, the pragmatic prerogative would be to proceed directly to surgical clipping. Nonetheless, we are of the opinion that endovascular treatment for intracranial aneurysms remains a valuable alternative to surgical clipping.

In our study, patients who underwent surgical clipping were 1.8 times more likely to require VP shunting than those who underwent coiling. However, this finding is inconsistent with those published in the current literature, where some studies have suggested that the number of patients undergoing VP shunts for hydrocephalus as a result of SAH may be reduced by proceeding with clipping instead of coiling. ${ }^{(13,14)}$ However, a few papers have also cited otherwise. ${ }^{(15)} \mathrm{A}$ possible explanation for this variation could be that patients who were selected for endovascular coiling in our study generally had bettergrade aneurysms compared to those who underwent surgical clipping due to interventional radiologists having the first-line of selection of patients, thus resulting in better outcomes and lower rates of VP shunting.

We also found a positive correlation among Fisher grade, hydrocephalus and the need for EVD insertion. Fisher grading is commonly used to predict the risk of SAH-associated vasospasm; (16) a higher grade on the Fisher scale indicates a higher probability of vasospasm. The accepted explanation for this observation is that with a higher Fisher grade, there is more blood within the subarachnoid space. ${ }^{(17)}$ Such blood products can cause physical obstruction within the ventricular system and may lead to microscopic obstruction of the arachnoid granulations, thereby giving rise to hydrocephalus. ${ }^{(18,19)}$

In summary, patients with good-grade aneurysmal SAH undergoing surgical clipping were 1.5 times more likely to have poor outcomes compared to those undergoing endovascular coiling, with an absolute difference of $5.2 \%$. This group of patients was also 1.8 times more likely to require a VP shunt at the end of their six-month follow-up. There was a significant positive association between Fisher grade and hydrocephalus. More studies are required to address the issue of bias in patient selection, so as to compare the efficacy and outcomes of neurosurgical treatment versus endovascular intervention for aneurysmal patients with SAH. The patient outcome aspect of our study is still ongoing.

We acknowledge that our institution has a slightly different approach in place for the management of ruptured intracranial aneurysms when compared to other overseas centres. As previously mentioned, our current practice is that all cases of aneurysms deemed fit to undergo treatment are initially discussed with interventional radiologists, and if possible, endovascular coiling is preferred to surgery. However, in spite of this confounding factor and in the context of our institution, the correlation of our results with current evidence-based findings indicate that surgical clipping of ruptured aneurysms provides similar and comparable long-term outcomes as endovascular coiling. ${ }^{(20-22)}$

\section{ACKNOWLEDGEMENTS}

We would like to thank A/Prof Ng Tze Pin of Yong Loo Lin School of Medicine, National University of Singapore, Singapore, for his valuable help and guidance with the statistical analysis of our data.

\section{REFERENCES}

1. Dupont SA, Wijdicks EF, Lanzino G, Rabinstein AA. Aneurysmal subarachnoid hemorrhage: an overview for the practicing neurologist. Semin Neurol 2010; 30:545-54.

2. Penn DL, Komortar RJ, Sander Connolly E. Hemodynamic mechanisms underlying cerebral aneurysm pathogenesis. J Clin Neurosci 2011; 18:1435-8.

3. Molyneux A, Kerr R, Stratton I, et al. International Subarachnoid Aneurysm Trial (ISAT) of neurosurgical clipping versus endovascular coiling in 2143 patients with ruptured intracranial aneurysms: a randomised trial. Lancet 2002; 360:1267-74.

4. McDougall CG, Spetzler RF, Zabramski JM, et al. The Barrow Ruptured Aneurysm Trial. J Neurosurg 2012; 116:135-44.

5. Molyneux AJ, Kerr RS, Birks J, et al. Risk of recurrent subarachnoid haemorrhage, death, or dependence and standardised mortality ratios after clipping or coiling of an intracranial aneurysm in the International Subarachnoid Aneurysm Trial (ISAT): long-term follow-up. Lancet Neurol 2009; 8:427-33.

6. Mayberg MR, Batjer HH, Dacey R, et al. Guidelines for the management of aneurysmal subarachnoid haemorrhage. A statement for healthcare professionals from a special writing group of the Stroke Council, American Heart Association. Stroke 1994; 25:2315-28.

7. Wardlaw JM, White PM. The detection and management of unruptured intracranial aneurysms. Brain 2000; 123:205-21. 
8. Hop JW, Rinkel GJ, Algra A, van Gijn J. Case-fatality rates and functional outcome after subarachnoid hemorrhage: a systematic review. Stroke 1997; 28:660-64.

9. Hoh BL, Kleinhenz DT, Chi YY, Mocco J, Barker FG 2nd. Incidence of ventricular shunt placement for hydrocephalus with clipping versus coiling for ruptured and unruptured cerebral aneurysms in the Nationwide Inpatient Sample database: 2002 to 2007. World Neurosurg 2011; 76:548-54.

10. Linn FH, Rinkel GJ, Algra A, van Gijn J. Incidence of subarachnoid hemorrhage: role of region, year, and rate of computed tomography: a meta-analysis. Stroke 1996; 27:625-9.

11. van Dijk JM, Groen RJ, Ter Laan M, Jeltema JR, Mooij JJ, Metzemaekers JD. Surgical clipping as the preferred treatment for aneurysms of the middle cerebral artery. Acta Neurochir (Wien) 2011; 153:2111-7.

12. Tidswell P, Dias PS, Sagar HJ, Mayes AR, Battersby RD. Cognitive outcome after aneurysm rupture: relationship to aneurysm site and perioperative complications. Neurology 1995; 45:875-82.

13. Nam KH, Hamm IS, Kang DH, Park J, Kim YS. Risk of shunt dependent hydrocephalus after treatment of ruptured intracranial aneurysms: surgical clipping versus endovascular coiling according to fisher grading system. J Korean Neurosurg Soc 2010; 48:313-8.

14. de Oliveira JG, Beck J, Setzer M, et al. Risk of shunt-dependent hydrocephalus after occlusion of ruptured intracranial aneurysms by surgical clipping or endovascular coiling: a single-institution series and meta-analysis. Neurosurgery 2007; 61:924-33.

15. Taha MM, Nakahara I, Higashi T, et al. Endovascular embolization vs surgical clipping in treatment of cerebral aneurysms: morbidity and mortality with short-term outcome. Surg Neurol 2006; 66:277-84.

16. Fisher CM, Kistler JP, Davis JM. Relation of cerebral vasospasm to subarachnoid hemorrhage visualized by computerized tomographic scanning. Neurosurgery 1980; 6:1-9.

17. Dorai Z, Hynan LS, Kopitnik TA, Samson D. Factors related to hydrocephalus after aneurysmal subarachnoid hemorrhage. Neurosurgery 2003; 52:763-9.

18. Ellington E, Margolis G. Block of arachnoid villus by subarachnoid hemorrhage. J Neurosurg 1969; 30:651-7.

19. Brydon H, Bayston R, Hayward R, Harkness W. The effect of protein and blood cells on the flow-pressure characteristics of shunts. Neurosurgery 1996; 38:498-505.

20. Al-Tamimi YZ, Ahmad M, May SE, et al. A comparison of the outcome of aneurysmal subarachnoid haemorrhage before and after the introduction of an endovascular service. J Clin Neurosci 2010; 17:1391-4.

21. Naidech AM, Janjua $N$, Kreiter KT, et al. Predictors and impact of aneurysm rebleeding after subarachnoid hemorrhage. Arch Neurol 2005; 62:410-6

22. Qureshi Al, Janardhan V, Hanel RA, Lanzino G. Comparison of endovascular and surgical treatments for intracranial aneurysms: an evidence-based review. Lancet Neurol 2007; 6:816-25.

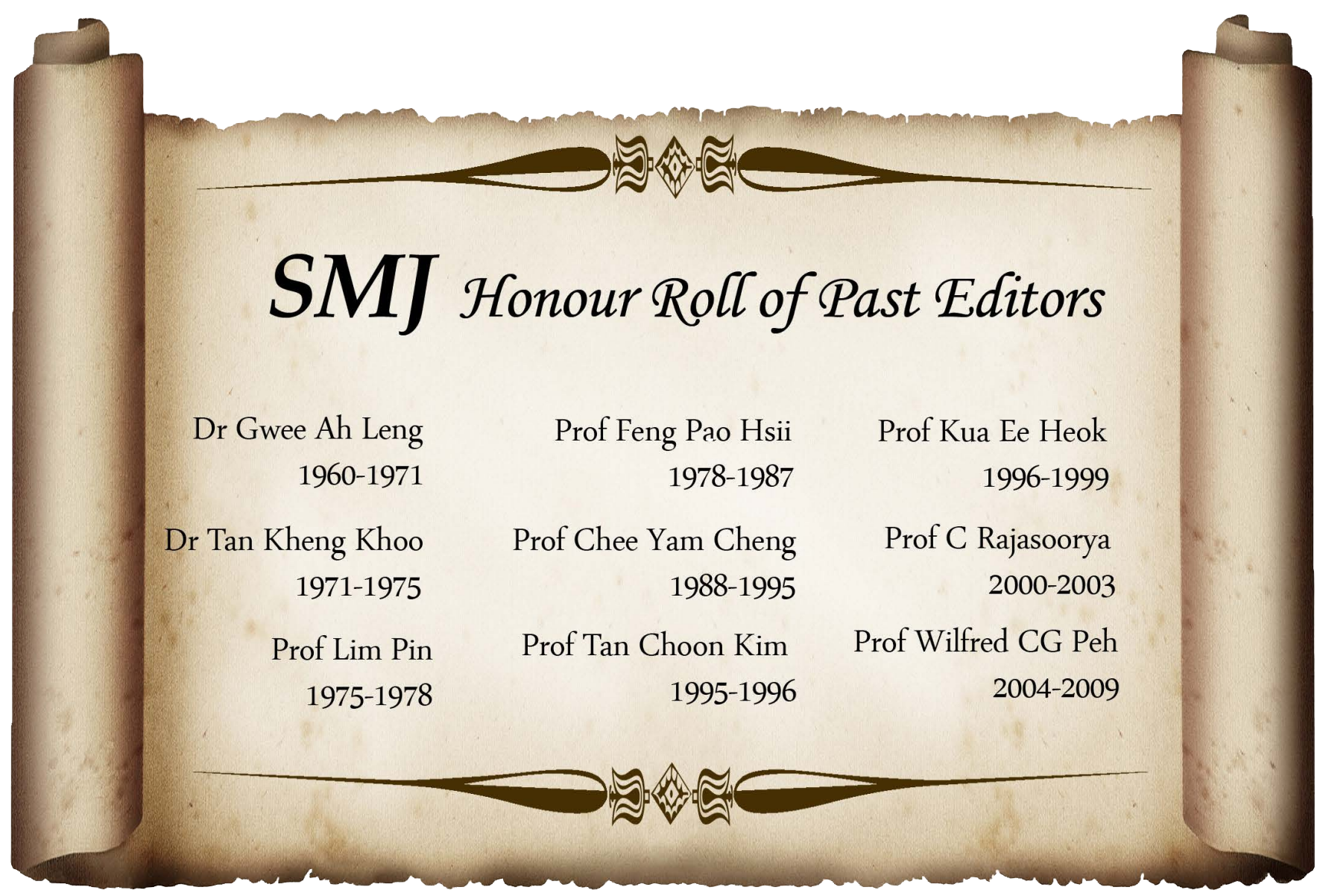

